\title{
Features of written texts of people with different profiles of Lateral Brain Organization of Functions (on the Basis of RusNeuroPsych Corpus)
}

\author{
Tatiana Litvinova ${ }^{1}$, Ekaterina Ryzhkova ${ }^{2}$, Olga Litvinova ${ }^{3}$ \\ ${ }^{1}$ Regional Centre for Russian Language, Voronezh State Pedagogical University, Russia \\ ${ }^{2}$ Department of Russian Language, Voronezh State University of Engineering \\ Technologies, Russia \\ ${ }^{3}$ Department of English Language, Voronezh State Pedagogical University, Russia \\ https://doi.org/10.36505/ExLing-2016/07/0023/000282
}

\begin{abstract}
The aim of the study is detection of typological characteristics of written texts created by people with different profiles of the lateral brain organization of functions (LBOF). The material of the study is a special Russian text corpus RusNeuroPsych containing metada about LBOF (motor, sensory, cognitive) of their authors. Numerical values of a range of formal language parameters (index of lexical diversity, frequencies of parts of speech, etc.) were extracted from 242 texts and statistically significant $(p<0.05)$ correlations between numerical values of a range of parameters of written texts and LBOF of their authors were identified for the first time for Russian texts.
\end{abstract}

Key words: written text, Russian, neuropsychology, brain lateralization, text corpus.

\section{Background}

One of the most important neuropsychological characteristics reflecting individual differences in the joint operation of the human brain hemispheres (asymmetry) is the lateral brain organization of functions (LBOF, Khomskaya et al. 1997). It is considered the foundation for the typology of individual differences of the mental condition of healthy individuals as part of a study in neuropsychology of individual differences. Neuropsychology of individual difference is an application of neuropsychological concepts and methods to the assessment of healthy subjects that tries to explain normal functioning by using principal of cerebral organization particularly characteristics of interhemispheric asymmetry and interaction (Glozman 2004, 838). The studies by Khomskaya et al. (1997) showed a stable correlation between the types of LBOF and different aspects of cognitive, motor and emotional activity of the normal subjects, which means that we have a correct foundation for the norm typology.

ExLing 2016: Proceedings of $7^{\text {th }}$ Tutorial and Research Workshop on Experimental Linguistics, 27 June - 2 July 2016, Saint Petersburg, Russia 
LBOF has an influence on the characteristics of the speech production as well (Shubin 2007) but this problem has not been sufficiently studied. There are mostly studies into the connection between the lateral brain organization and types of speech disorders (e.g., see Gudkova 2010), ways of formation of speech, acquisition of reading and writing skills (Litvinova 2013).

According to the literature, the connection between the lateral brain organization and characteristics of a written discourse of healthy individuals has not been dealt with and this is why the ongoing research project is of significance. We hypothesize that the lateral brain organization of functions impacts the characteristics of a produced written discourse and the classification of individuals according to their lateral brain organization can be used as the basis for a classification of language personalities.

\section{Aim of the study}

The aim of the study is to detect typological characteristics of coherent written texts created by people with different profiles of the lateral brain organization of functions using methods of statistical analysis and corpus linguistics.

\section{Experimental study Material}

In order to address this problem it is necessary to create the corpus of written texts containing information about the type of LBOF of their authors. The text corpus Rus NeuroPsych created under the guidance of the authors currently contains 643 Russian-language written texts by 447 authors (native Russian speakers) from 12 to 35 years of age. RusNeuroPsych corpus contains metadata in the form of information about their authors: year of birth, gender, native language, education, the results of psychological testing and survey for identifying their motor, sensory and cognitive lateral profile using the most indicative and simple tests (see Sirotyuk 2003, Semago 2005, Balonov 1985). The index of the lateral brain organization (motor, cognitive, sensory as well as individually for hands, legs, eyes, ears) was calculated as the difference between the number of "right", "left" and "symmetrical" answers divided into the number of tests. An integral index of LBOF was also computed as the difference between the number of "right", "left" and "symmetrical" answers divided into the number of tests. 
For the present study 242 texts by 121 respondents (each respondent wrote two texts - letter to a friend and description of a picture) aged from 24 to 35, 17 men, 104 women, were selected. The average length of text is 165 words.

\section{Methods}

The texts were marked with the help of a morphological analyzer polymorpy 2 and online service istio.com and the numerical values of the formal-grammar parameters of texts were obtained (indices of lexical diversity of texts, frequencies of different parts of speech and their ratios and other frequent parameters that occur in texts regardless of their topic and genre, 22 in total). SPSS Statistics software was used to calculate the Pearson coefficient between the text parameters and indices of LBOF. Two series of experiments were conducted: in the first one both texts by the same author were considered as one ("a sum corpus") and in the second one two texts were considered individually ("an individual corpus").

\section{Results}

Significant correlations $(\mathrm{p}<0.05)$ between the formal-grammar parameters of written texts and the type of LBOF of their authors which were observed in two series of the experiments were revealed. The largest number of correlations of the parameters $(\mathrm{r}=0.27-0.41)$ of texts were found with $\mathrm{LBOF}_{\text {motor }}(8), \mathrm{LBOF}_{\text {hands }}(8), \mathrm{LBOF}_{\text {integral }}(7)$. There were much fewer significant correlations found with the indices of sensory and cognitive asymmetry except $\mathrm{LBOF}_{\text {eyes }}$ (5). A positive correlation of the indices of $\mathrm{LBOF}_{\text {hands }}, \mathrm{LBOF}_{\text {motor }}$ and $\mathrm{LBOF}_{\text {integral }}$ with the index of lexical diversity TTR was identified and a negative one with a proportion of function words + pronouns; proportion of function words; proportion of cognitive words; proportion of full stops; proportion of 100 most frequent Russian words, i.e. the more right properties there are in the human LBOF, the higher is the lexical diversity of their texts and the fewer function words, pronouns, full stops, most frequent words they have.

\section{Conclusions and future work}

Our pilot research proved studies of the connection between parameters of texts and LBOF of their authors promising. There will have to be more respondents considering their gender distribution as well as more text parameters. One of future studies will be looking at the causes of the 
identified correlations. It is also planned to conduct a correlationregression analysis to construct mathematical models allowing one based on the formal-grammar text parameters to predict the type of LBOF of their authors (cf. Juola 2013), as well as to search for correlations between the type of LBOF and other characteristics of the authors of texts (gender, age, data of psychological testing).

\section{Acknowledgements}

The study is financially supported by the grant of RFBR "Linguistic Parameters of a Written Text and Neuropsychological Characteristics of its Author: A Corpus Study", project number 16-36-00036.

\section{References}

Balonov L. Ya., Deglin, V. L. and Chernigovskaya T. V. 1985. Functional Brain Asymmetry in Speech Organization. In Sensory Systems. Sensory Processes in Hemisphere Asymmetry. Leningrad, Science.

Glozman, J. 2004. Russian neuropsychology after Luria. In Craighead, W., Nemeroff Ch. (eds.). The Concise Corsini Encyclopedia of Psychology and Behavioral Science. NY, Wiley \& Sons.

Gudkova, T. V. 2010. Features of Functional Sensomotor Asymmetry in Preschool Children with a General Speech Disorder. PhD thesis. Saint Petersburg, Herzen State Pedagogical University of Russia.

IBM SPSS Statistics 22 Documentation. http://www01.ibm.com/support/docview.wss?uid $=$ swg27038407\#ru

Juola, P., Neocker, Jr. J., Stolerman, A., Ryan, M., Brennan, P. and Greenstadt, R. 2013. Keyboard Behavior Based Authentication for Security. IEEE IT Professional, 15, 4, 8-11, July-Aug.

Khomskaya, Ye.D., Yefimova, I.V., Budyka, Ye.V. and Yenikolopova, Ye.V. 1997. Neuropsychology of Individual Differences (Left-Right Brain and Mental Condition). Moscow, Russian Pedagogical Agency.

Litvinova, G. V. 2013. Effect of Lateral Organization on the Formation of Speech in Children. Petropavolvsk-Kamchatskiy, Vitus Bering Kamchatka State University.

Semago, N. Ya. and Semago, M. 2005. Theory and Practice of the Evaluation of Mental Development of a Child. Preschool and Junior School Age. Saint Petersburg, Rech.

Shubin, A.V. and Serpionova, Ye.I. 2007. Brain Asymmetry and Features of Verbal Creativity. Voprosy psikhologii 4, 89-97.

Sirotyuk, A.L. 2003. Neuropsychological and Psychophysiological Learning Component. Moscow, Sfera. 